\title{
Two-Parameter Gloss Methods
}

\section{Nimeroff}

\begin{abstract}
The concept of a parameter of glossiness, that is, measurement under one set of illuminating and viewing conditions, is developed. To describe completely the glossiness of a specimen requires multiparametric measurements on the geometric distribution of reflected light-flux. As one-parameter methods have been found to yield inadequate descriptions of specimen glossiness, two-parameter methods were investigated. For specimens with differing incidence-angle dependency, a two-parameter method using specular gloss measurements at two incidence angles is suggested. For specimens with differing flux-scattering characteristics, a two-parameter method using specular gloss measurements for two receptor apertures is suggested. Several existing standard two-parameter methods are reviewed. Results of a seven-laboratory round-robin test of the two-parameter (receptor aperture) method are reported and analyzed. To establish correlation between measurements obtained with the suggested two-parameter (receptor aperture) method and subjective evaluation of image brightness and image distinctness, a subjective test was formulated. The results of this test, here analyzed and discussed, indicate the usefulness of the two-parameter method.
\end{abstract}

\section{Introduction}

For many years American Society for Testing Materials committee deliberations on glossimetry definitions have been concerned with use of terms like "aspects," "criteria," "modes," and "types" of gloss in describing instrumental measurement techniques found to correlate with some glossiness characteristics. Glossiness, or glossy appearance, is a function of how an observer evaluates the geometric distribution of flux reflected by a specimen. To evaluate completely this appearance characteristic, called glossiness, observations under many conditions of illumination and view are required. A measurement under each illuminating and viewing condition may be called a parameter of glossiness.

Techniques involved in methods for evaluating of specimens have ranged from one-parameter to multiparameter observations. The multiparameter technique is complex, time consuming, and too costly to perform for every specimen. While a one-parameter technique can yield data simply, rapidly, and inexpensively, it is an oversimplified solution to the problem of instrumental evaluation of gloss characteristics. One-parameter data often lead to erroneous conclusions about the comparative appearance of specimens. To decrease the number of erroneous conclusions without materially inincreasing the complexity, time, and cost of the measurement, a compromise between a one-parameter and a multiparameter technique is required.

\section{Multiparameter Technique}

\subsection{Multiplane Goniophotometry}

Multiparametric observations can be taken on either multiplane or monoplane instruments, called goniophotometers. A multiplane goniophotometer would have many geometric variables at its disposal. Such an instrument was designed and constructed by McNicholas [1]. ${ }^{1}$ Figure 1 shows the geometric variables: $\theta$, the angle between the axis of the incident

\footnotetext{
${ }^{1}$ Figures in brackets indicate the literature references at the end of this paper.
}

beam and the perpendicular to the specimen plane; $\phi$, the azimuth angle (the angle between a reference line in the plane of the specimen and the projection of the incident axis on that plane); $\omega$, the solid angular subtense, or aperture, of the incident beam; $\theta^{\prime}, \phi^{\prime}$, and $\omega^{\prime}$, the corresponding geometric variables of the reflected beam.

If the goniophotometric readings for a specimen under each set of illuminating and viewing conditions (parameters) are represented by $G_{i, r}$, where $i$ refers to the incident beam, and $r$ refers to the reflected beam, the complete gloss description of the specimen, $G_{\phi}$, would be a function of these parameters. This may be symbolically stated:

$$
G_{\phi}=F\left(G_{i, r}\right),
$$

where $i$ is dependent on $\theta, \phi$, and $\omega$, and $r$ is dependent on $\theta^{\prime}, \phi^{\prime}$, and $\omega^{\prime}$. This dependence may be stated:

$$
\left.\begin{array}{l}
i=f(\theta, \phi, \omega) \\
r=g\left(\theta^{\prime}, \phi^{\prime}, \omega^{\prime}\right) .
\end{array}\right\}
$$

An analysis of goniophotometric data can be considered as a solution of eq (1) for the functional description, $F\left(G_{i, r}\right)$. Thaler [2] published a rather complete set of parametric measurements for a series of $\mathrm{MgO}$ specimens, using constant $\omega$ and $\omega^{\prime}$, but did not develop a functional description of the appearance of the material.

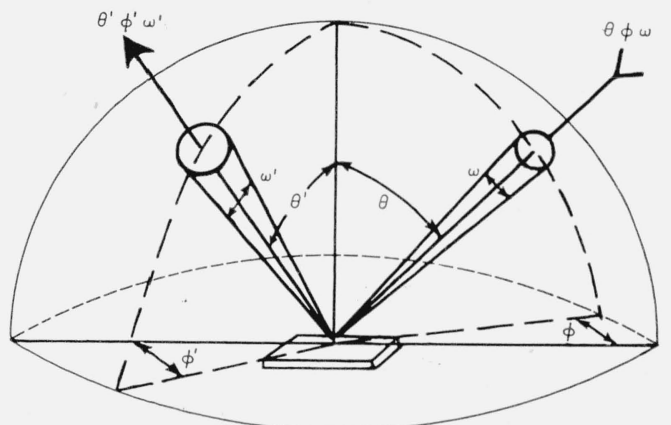

FIGURE 1. Geometric variables of a multiplane goniophotometer 


\subsection{Monoplane Goniophotometry}

A monoplane instrument has one less variable at its disposal than a multiplane instrument. The variables of a monoplane goniophotometer are those of figure 1 , except that $\phi^{\prime}=\phi$. The variables are $\theta$ and $\omega$ for the incident beam, $\theta^{\prime}$ and $\omega^{\prime}$ for the reflected beam. If rectangular source and receptor are substituted for the circular ones, the angular sizes $\omega$ and $\omega^{\prime}$ become $\alpha \beta$ and $\alpha^{\prime} \beta^{\prime}$, respectively. Goniophotometers of this type have been designed and constructed by Wetlaufer and Scott [3], Moon and Laurence [4], Hammond and Nimeroff [5], and Middleton and Mungall [6].

For this type of instrument, the gloss description of the specimen, $G$, could be symbolically represented by:

$$
G=F\left(G_{i, \tau}\right),
$$

where $i$ is dependent on $\theta, \alpha$, and $\beta$, and $r$ is dependent on $\theta^{\prime}, \alpha^{\prime}$, and $\beta^{\prime}$. This dependence is stated:

$$
\left.\begin{array}{l}
i=f[\theta,(\alpha \beta)] \\
r=g\left[\theta^{\prime},\left(\alpha^{\prime} \beta^{\prime}\right)\right] .
\end{array}\right\}
$$

Analyses of goniophotometric data obtained on this type of instrument have been made. Barkas [7] suggested a method for theoretically separating the specular and diffuse reflection components of a specimen by finding an equivalent theoretical surface that will have the same goniophotometric reflectance as the specimen. Middleton and Mungall [6] suggested a similar analysis for goniophotometric data. These analyses were confined to fairly matte surfaces, such as beaverboard and snow.

ASTM Method, D636-54 [8] recommends use of a Dows-Baumgartner reflectometer [9] and analysis of its goniophotometric data in terms of reflective diffusion indexes:

$$
\left.\begin{array}{l}
D_{r a}=\frac{\int_{3^{\circ}}^{90^{\circ}} R\left(\theta^{\prime}\right) d \theta^{\prime}}{97 R\left(3^{\circ}\right)} \\
D_{r b}=\frac{\int_{15^{\circ}}^{90^{\circ}} R\left(\theta^{\prime}\right) d \theta^{\prime}}{75 R\left(15^{\circ}\right)},
\end{array}\right\}
$$

where $R\left(\theta^{\prime}\right)$ is the reflectance at viewing angle, $\theta^{\prime}$. The specimen is illuminated perpendicularly, $\theta=0^{\circ}$.

Analysis of goniophotometric data for specimens ranging in gloss from matte to highly specular was made by Nimeroff [10]. The goniophotometric data were analyzed in terms of indexes of dispersion, skewness, and kurtosis (peakedness index), related to the second, third, and fourth moments, respectively.

\section{One-Parameter Technique}

\subsection{Specular Glossmeters}

One-parameter instruments that have been developed recently have been monoplanar with fixed source and receptor apertures and fixed incidence and specular reflecting angles. Symbolic representation for the geometry of such a one-parameter instrument is

$$
\left.\begin{array}{l}
i=f[\theta,(\alpha \beta)] \\
r=g\left[-\theta,\left(\alpha^{\prime} \beta^{\prime}\right)\right] .
\end{array}\right\}
$$

Specular glossmeters have been developed for at least five different incidences angles, $20^{\circ}, 45^{\circ}, 60^{\circ}$, $75^{\circ}$, and $85^{\circ}$, and are described in ASTM, PEI, and TAPPI gloss methods. These methods have proven satisfactory except for occasional confusion resulting from inadequacy of a one-parameter technique.

\subsection{Inadequacies of the One-Parameter Technique}

Specular reflectance of a specimen depends on the angle at which light flux is incident on the specimen. For some specimens the rate of increase of specular reflectance with increasing incidence angles exceeds the rate for other specimens. Thus two specimens can have the same gloss when illuminated at one incidence angle and have much different gloss when illuminated at another incidence angle. A oneparameter technique, specular reflectance measurement at one set of geometric conditions, will not reveal this incidence-angle dependency of the appearance of these specimens.

More frequently than in the above instance, inadequacy of a one-parameter technique is demonstrated when one specimen has a more peaked distribution of reflected flux than the other. Even though two such specimens may differ markedly in appearance, the flux reflected from one specimen and accepted by the receptor may equal the accepted flux reflected from the other specimen. The instrument, therefore, will indicate that both specimens have the same gloss in spite of their difference in appearance.

\section{Two-Parameter Techniques}

A two-parameter monoplane technique would provide for two variations of geometry. ASTM Method of Test for Mar Resistance of Plastics [11], Designation D673-44T, requires a two-parameter instrument that measures flux reflected on the specular angle, $45^{\circ}$, and at an angle displaced $15^{\circ}$ from the specular angle, namely, $30^{\circ}$. The geometry of that instrument can be represented as

$$
\left.\begin{array}{l}
i=f\left[45^{\circ},(\alpha \beta)\right\} \\
r=g\left[45^{\circ}, 30^{\circ},\left(\alpha^{\prime} \beta^{\prime}\right)\right] .
\end{array}\right\}
$$

The data obtained by this method are analyzed in terms of percentage of gloss thus: Gloss, percent $=$ $100\left[1-\left(G_{45,30} / G_{45,45}\right)\right]$, where $\mathrm{G}$ is the instrument reading for the geometry indicated by the subscripts.

Middleton and Mungall [12] described a distinctness-of-image glossmeter designed to use the maximum slope of the goniophotometirc curve as the gloss index of a specimen. This instrument measures flux reflected from a specimen at the specular angle, $45^{\circ}$, and at an angle displaced $\Delta \theta$ from the specular 
angle. The geometry of that instrument can be represented as

$$
\left.\begin{array}{l}
i=f\left[45^{\circ},(\alpha \beta)\right], \\
r=g\left[45^{\circ}, 45+\Delta \theta,\left(\alpha^{\prime} \beta^{\prime}\right)\right] .
\end{array}\right\}
$$

The instrument analyzes the data thus obtained in terms of a gloss index. Gloss index $=\left(G_{45,45}-\right.$ $\left.G_{45,45+\Delta \theta}\right) / \Delta \theta$, where $G$ is the instrument reading for the geometry indicated by the subscripts.

For two-parameter glossmeters of the specular type the two variations of geometry would be variation of the specular angle or variation of the size of the receptor aperture. The symbolic representation for the geometry of a two-parameter instrument designed for measurements at two specular angles might be written

$$
\left.\begin{array}{c}
i=f\left[\theta_{1}, \theta_{2},(\alpha \beta)\right], \\
r=g\left[\theta_{1}, \theta_{2},\left(\alpha^{\prime} \beta^{\prime}\right)\right] .
\end{array}\right\}
$$

The geometry for such an instrument is shown in figure 2. The symbolic representation for the geometry of a two-parameter instrument designed for measurements with two receptor apertures might be

$$
\left.\begin{array}{l}
i=f\left[\theta,\left(\alpha_{1} \beta_{1}\right),\left(\alpha_{2} \beta_{2}\right)\right], \\
r=g\left[\theta,\left(\alpha_{1}^{\prime} \beta_{1}^{\prime}\right),\left(\alpha_{2}^{\prime} \beta_{2}^{\prime}\right)\right] .
\end{array}\right\}
$$

The geometry for such an instrument is shown in figure 3.

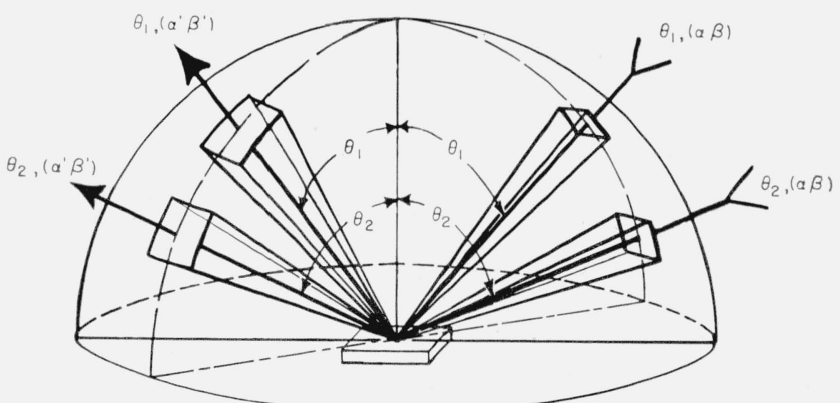

Figure 2. Geometry of an incidence angle two-parameter glossmeter.

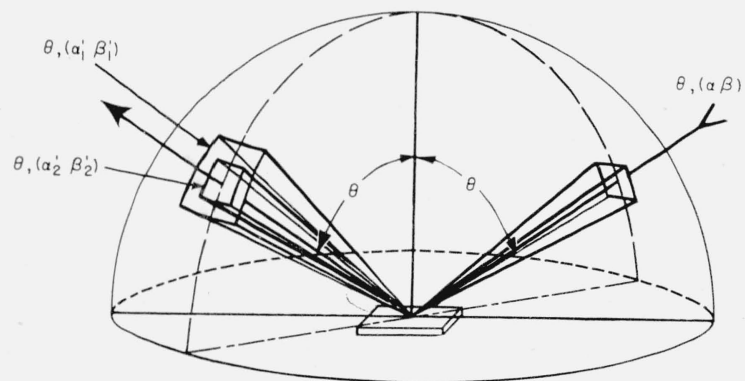

FIgI 3. Geometry of a receiver aperture two-parameter glossmeter.

\subsection{Specular Angle}

To illustrate how a two-parameter instrument might be used to resolve problems where specularangle dependence is important, two low-gloss specimens were selected. These specimens appear to have nearly equal gloss when viewed at angles ranging from perpendicular to about $65^{\circ}$. At angles greater than $65^{\circ}$ one specimen appears considerably glossier than the other. Figure 4 shows plots of fractional reflectance, the ratio of flux reflected within a $0.6^{\circ}$ cone to the incident flux, as a function of angle, $d$, between the viewing direction and that of mirror reflection as measured on a monoplane goniophotometer. The specimens are designated A and B. At $60^{\circ}$ incidence both curves are flat (reflected flux is uniformly distributed) with A having a slightly higher fractional reflectance. At $80^{\circ}$ incidence the curve for A remains reasonably flat, whereas that for B becomes quite peaked, having a peakedness index of 182 compared with 1.9 for A. Peakedness index for a unimodal curve was shown by Nimeroff [10] to be an index of the relative peak to shoulder heights.

A goniophotometer, arranged for the $60^{\circ}$ geometry of ASTM Method D523-53T, [13] was used to measure the specular gloss of specimens $\mathrm{A}$ and $\mathrm{B}$ for $60^{\circ}$

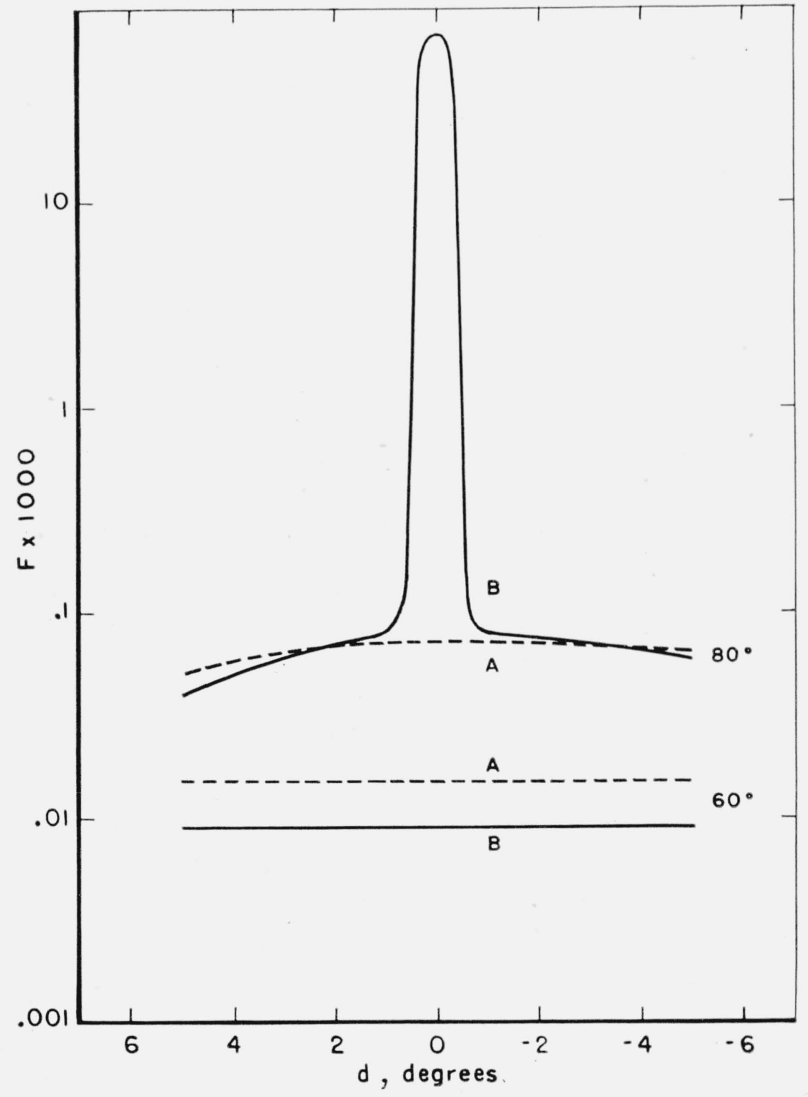

Figure 4. Fractional reflectance curves for two specimens exhibiting incidence-angle dependency at incidence angles of $60^{\circ}$ and $80^{\circ}$. 
and $80^{\circ}$ incidence. At $60^{\circ}$ incidence, the gloss reading for $\mathrm{A}$ is 6 and for $\mathrm{B}$ is 4 , whereas at $80^{\circ}$ incidence the gloss reading for $\mathrm{A}$ is 24 and for $\mathrm{B}$ is 109 . These readings show the much stronger incidence-angle dependence for $\mathrm{B}$ than for $\mathrm{A}$. This dependence is not suggested in a measurement of specular oloss at $60^{\circ}$ incidence alone.

The solution to problems involving incidence-angle dependence is obvious. Measure the specular gloss at two incidence angles and relate the resulting data. The slope of the line joining plotted points of the gloss readings for a specimen obtained with two incidence angles may be used as an index of the dependence of gloss on incidence angle.

\subsection{Receptor Aperture}

Appearance characteristics ascribable to gloss may be classified into three distinct types, either in accord with appearance or in accord with fluxscattering properties. Appearance wise, the two extreme types are image-forming and nonimage forming; the third type exhibits intermediate characteristics. Goniophotometric distributions for specimens of the image-forming type are shown in figure 5 . These curves are characterized by sharp peaks near the specular angle, with scattering at wide angles from the specular. As a considerable amount of scattered flux is found at wide angles, these specimens may be called "wide-angle scatterers." Goniophotometric distributions for specimens of the nonimage-forming type are shown in figure 6 . These

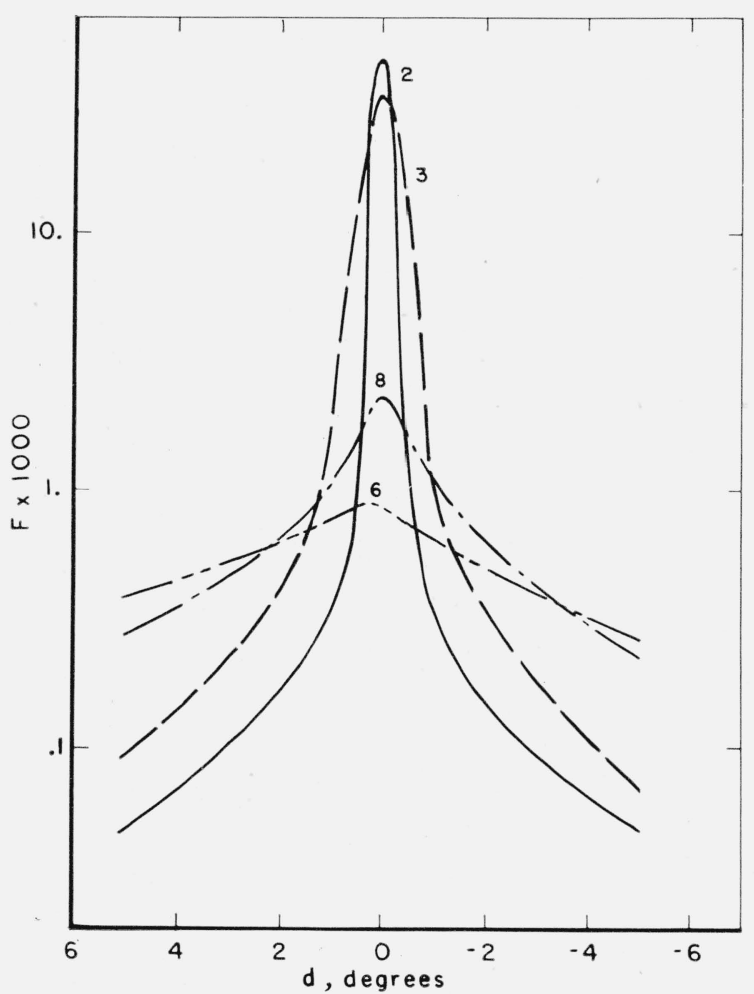

FiguRE 5.-Fractional reflectance curves for wide-angle scatterers.

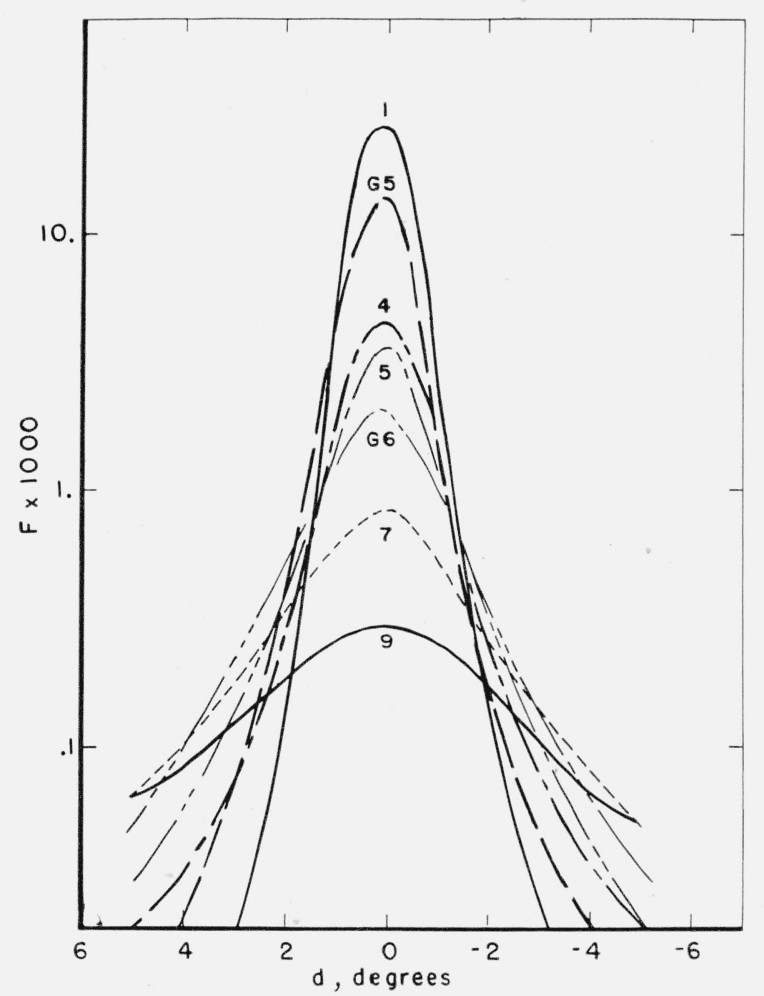
Figure 6.-Fractional reflectance curves for narrow-angle
scatterers.

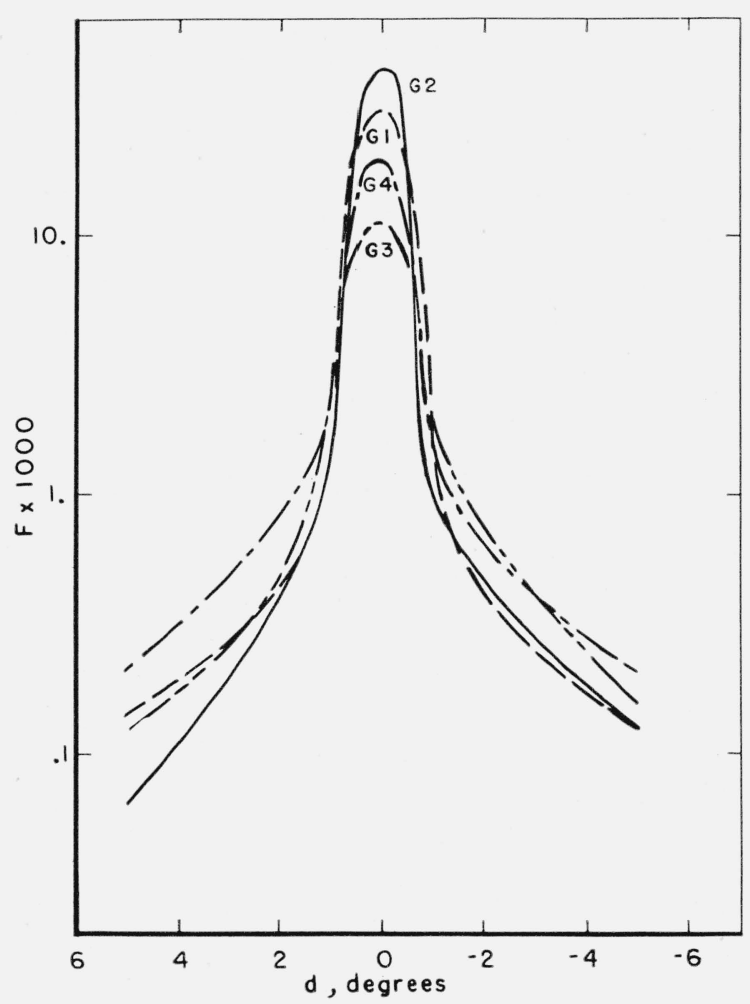

FIGURE 7.-Fractional reflectance curves for intermediate-angle scatterers. 


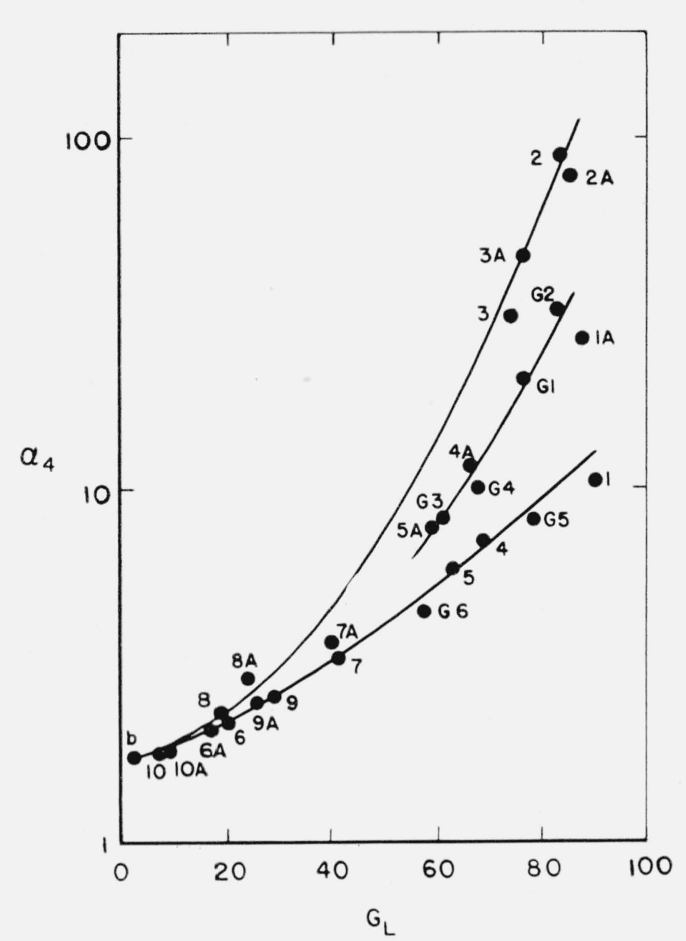

Figure 8. Plot of peakedness index, $\alpha_{4}$, against $60^{\circ}$ specular glossmeter readings, $G_{L}$, showing separation into three groups.

curves are are characterized by broad peaks with very little wide-angle scattering. As the scattering is confined to angles near the specular angle, these specimens may be called "narrow-angle scatterers," or "near-specular scatterers." Goniophotometric distributions for specimens of the intermediate type are shown in figure 7 . These curves are characterized by peaks broader than those for the wideangle scatterers but narrower than those for the narrow-angle scatterers. Such specimens might be called "intermediate-angle scatterers."

Nimeroff $[10]$ showed that two parameters are required to reveal instrumentally the two extreme types of specimen appearance due to scattering. Figure 8 shows separation of the three types using the ASTM $60^{\circ}$ specular oloss readings [7] and the peakedness indexes, $\alpha_{4}$, obtained from analysis of goniophotometric curves of the specimens, some of which are shown in figures 5,6 , and 7 .

\section{Gloss of Transparent Finishes}

Recently a problem arose in correlating the measured gloss with the observed appearance of transparent finishes applied to wood substrates. Difficulty was encountered in the measurement of the gloss of these finishes in that one-parameter techniques failed to yield data consistent with visual evaluation of the glossy appearance. In seeking a technique that would correlate with visual evaluations, 26 specimen panels were prepared by the Sherwin-Williams Co. and the Grand Rapids Varnish
Co. Goniophotometric curves of representative panels are shown in figures 5,6 , and 7 .

As stated above, a two-parameter technique was indicated as a possible solution to this problem. The slope of the monoplanar geometric distribution might be a useful representation of the gloss. An indication of the slope can be obtained from the ratio of a reading at the peak to a reading at the shoulder of a goniophotometric curve. The large receptor aperture used with the $60^{\circ}$ geometry of ASTM Method D523 provides a measure of the sum of the peak and shoulders of the reflected flux distribution. A receptor aperture small enough to measure only the flux about the peak of a distribution was needed to supplement the reading with the larger aperture so that the slope of the flux distribution of a specimen can be evaluated:

$$
\text { Slope }=\frac{2 G_{S}-G_{L}}{\alpha_{1}^{\prime} \beta_{1}^{\prime}-\alpha_{2}^{\prime} \beta_{2}^{\prime}}
$$

where $G_{S}$ is the instrument reading for the small receptor aperture, $\alpha_{1}^{\prime} \beta_{1}^{\prime}$, and $G_{L}$ is the instrument reading for the large receptor aperture, $\alpha_{2}^{\prime} \beta_{2}^{\prime}$. The small receptor aperture arbitrarily chosen is $\alpha_{1}^{\prime} \beta_{1}^{\prime}=$ $2.0^{\circ} \times 4.5^{\circ}$. The larger aperture already prescribed by Method D523 is $\alpha_{2}^{\prime} \beta_{2}^{\prime}=4.4^{\circ} \times 11.7^{\circ}$.

Measurement of the slope by this procedure is useful over regions of a curve where the slope is constant. As the goniophotometric curves of most specimens do not have constant slope, other relationships between $G_{L}$ and $G_{S}$ were sought. Several graphical representations of data were considered.

Figure 9 shows specular gloss data taken with the large aperture, $G_{L}$, plotted against data taken with the small aperture, $G_{S}$, for the specimens whose

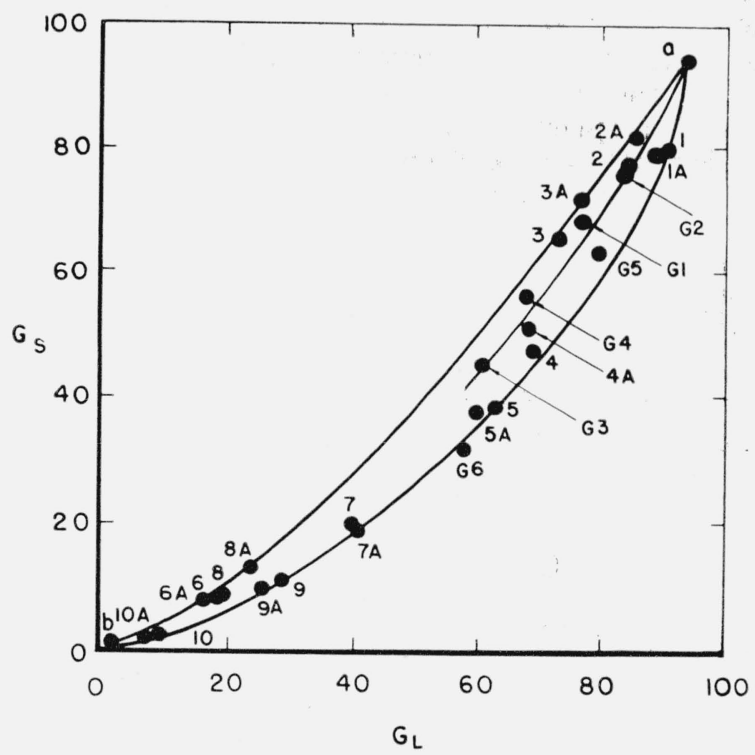

Figure 9. Plot of glossmeter readings with small aperture against those with large. 


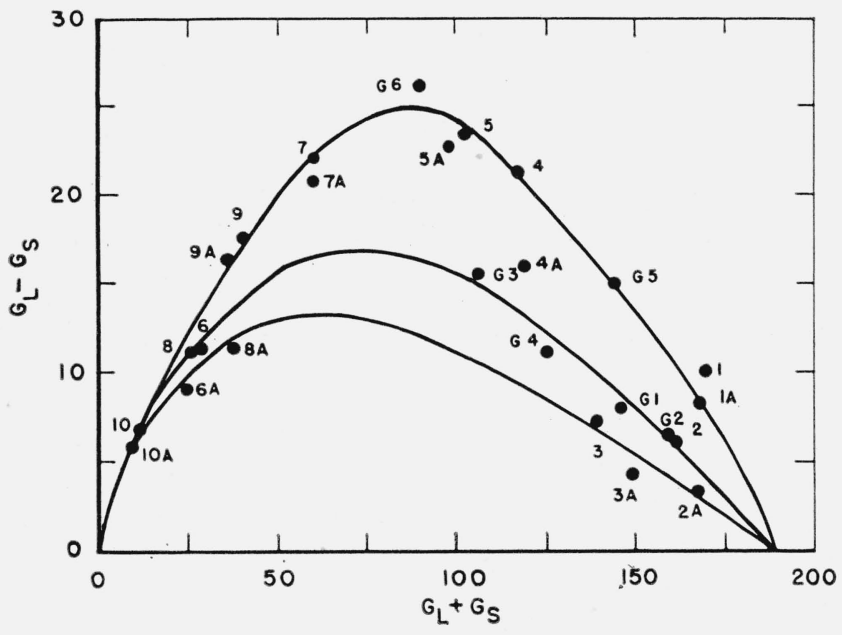

Figure 10. Plot of differences, $D=G_{L}-G_{S}$, against sums, $S=G_{L}+G_{S}$.

goniophotometric curves were shown earlier. The three branches that result are consistent with the separation into appearance types, as evidenced by the goniophotometric data. As aperture reduction stops more flux for narrow-angle scatterers than for wide-angle scatterers the data for the former lie in the lower branch. The plotted points in each branch lie in a sequence consistent with the order of the peaks of the goniophotometric curves for the specimens represented. The curve for a group of intermediate scatterers lies between those for the extreme types.

Terminal points $a$ and $b$ (fig. 10) occur at the indicated locations for the following reasons: If a receiver aperture is reduced to a size just larger than the source image the reading for a perfectly polished specimen is not varied because all the flux reflected from the surface of a polished specimen will enter the receiver if the receiver aperture is larger than the source image. Point a represents the specular gloss of a specimen of polished glass of index 1.527 and is plotted at 93.6 on both scales.

When a receiver aperture is reduced in area the glossmeter reading for a perfect diffuser will be reduced by the ratio of the areas. The glossmeter reading of a perfect diffuser for the receiver aperture of the $60^{\circ}$ geometry of ASTM Method D523 was reported by Hammond and Nimeroff [5] to be 2.1. As the ratio of large to small receiver entrance window is 5.7 , point $b$ is plotted at $G_{L}$ equal to 2.1 and $G_{S}$ equal to 0.37 .

\section{Round-Robin Test}

A round-robin test was undertaken on 26 specimens to evaluate data reproducibility, data repeatability, and specimen classification by the twoparameter (receptor aperture) method for specular gloss. By these terms are meant the following:

1. Data repeatability (within laboratory preci- sion): Repetition by each laboratory of data obtained at that laboratory to within a reasonably small tolerance.

2. Data reproducibility (between laboratory variability): Reproduction by each laboratory of data obtained by the other laboratories to within a reasonably small tolerance.

3. Specimen Classification: The existence of at least three classes of gloss characteristics that can be distinguished by a two-parameter gloss technique.

\subsection{Analysis of Round-Robin Data}

The data resulting from the round-robin are shown in table 1.

To test repeatability and reproducibility we select a suitable mathematical model. The model used here for the measurement of the $i$ th specimen in the $j$ th laboratory is

$$
y_{i j}=t_{t}+L_{j}+\epsilon_{i j},
$$

where $y_{i j}$ is the measurement, $t_{i}$ is the population, or "true," value of the measurement, $L_{j}$ is a random variable having an average value of zero and variance $\sigma_{L}^{2}$, which reflects the variability between laboratories, and $\epsilon_{i j}$ is a random variable having an average value of zero and variance $\sigma_{j}^{2}$, which reflects the precision for laboratory $j$.

\section{a. Repeatability}

A duplicate measurement is denoted by a prime, as $y_{i j}^{\prime}$. Then the difference between duplicate measurements is a quantity $d_{l j}$, thus

$$
d_{i j}=y_{i j}-y_{i j}^{\prime}=\epsilon_{i j}-\epsilon_{i j}^{\prime}
$$

having an average value of zero and variance $2 \sigma^{2}$. Thus if there is no reason to believe that the withinlaboratory error varies with the different specimens, the variance $\sigma_{j}^{2}$ of each laboratory for the 26 specimens can be estimated by means of the equation.

$$
s_{j}^{2}=\frac{\sum_{i} d_{i j}^{2}}{2 n}=\frac{d_{1 j}^{2}+\ldots+d_{26 j}^{2}}{52} .
$$

Systematic errors in duplicate measurements of $G_{L}$ by laboratories 2 and 5 and of $G_{S}$ by laboratory 2 were detected and eliminated from the estimates of precision for the determinations. Systematic errors in duplicate measurements for a laboratory are those in which $d_{i j}$ is the same sign for all or most specimens. This error is evident when the average value for all specimens differs appreciably from zero. The results for each laboratory are given in table 2 .

The variance of the within-laboratory data is of the same order of magnitude for all laboratories when systematic errors are eliminated from the estimates of variance. The average variance, $s^{2}$, within laboratories is 0.217 for $G_{L}$ when $s_{5}^{2}$ is eliminated, and 0.212 for $G_{S}$ when $s_{2}^{2}$ is eliminated. Thus repeatability for $G_{L}$ is approximately equal to that and $G_{S}$ and both variances are reasonably small. 
TABLE 1. Data for round-robin test

\begin{tabular}{|c|c|c|c|c|c|c|c|c|c|c|c|c|c|c|}
\hline \multirow{2}{*}{$\begin{array}{l}\text { Speci- } \\
\text { men }\end{array}$} & \multicolumn{7}{|c|}{$G_{L}$ for laboratory- } & \multicolumn{7}{|c|}{ Gs for laboratory- } \\
\hline & 1 & 2 & 3 & 4 & 5 & 6 & 7 & 1 & 2 & 3 & 4 & 5 & 6 & 7 \\
\hline & $\int 90.7$ & 90.5 & 89.8 & 90.0 & 90.0 & 89.5 & 88.4 & 79.4 & 77. 3 & 77.0 & 79.0 & 81.0 & 83.3 & 73.1 \\
\hline 1 & $\{90.4$ & 90.6 & 90.0 & 90 & 92 & 89.3 & 89.1 & 80.2 & 79.1 & 79.2 & 79 & & 84.2 & 72.4 \\
\hline $1 \mathrm{~A}$ & $\left\{\begin{array}{l}89.5 \\
87\end{array}\right.$ & 86.1 & $\begin{array}{l}87.6 \\
88.2\end{array}$ & 88 & 91 & 86.7 & 86.8 & 74.3 & 71.1 & 83.1 & 81 & 77 & 84.5 & 81.5 \\
\hline $1 \mathrm{~A}$ & 87.5 & $\begin{array}{r}88.8 \\
83.3\end{array}$ & 88.8 & $\begin{array}{l}89 \\
84\end{array}$ & 92 & 85. 0 & 87.5 & 75.8 & 79.8 & 84.5 & 82 & & 86.5 & 80.9 \\
\hline 2 & $\left\{\begin{array}{l}83.8 \\
83.6\end{array}\right.$ & $\begin{array}{l}83.3 \\
84.1\end{array}$ & $\begin{array}{l}82.2 \\
83.0\end{array}$ & ${ }_{83}^{84}$ & $\begin{array}{l}86 \\
87\end{array}$ & 83.9 & 80.4 & 79.1 & 77.8 & 76. 2 & 77 & 78 & 77.0 & 73.7 \\
\hline & 84.6 & 84.7 & 84.4 & 85 & 88 & $\begin{array}{l}84.5 \\
85.0\end{array}$ & $\begin{array}{l}80.9 \\
81.9\end{array}$ & $\begin{array}{l}79.3 \\
82.6\end{array}$ & 82.7 & $\begin{array}{l}76.1 \\
83.2\end{array}$ & $\begin{array}{l}77 \\
82\end{array}$ & 81 & 78.8 & 73.1 \\
\hline $2 \mathrm{~A}$ & $\{85.5$ & 85.7 & 85.0 & 85 & 88 & 85.1 & 82.1 & 82.9 & 82.3 & $\begin{array}{l}8.3 .2 \\
83.1\end{array}$ & $\begin{array}{l}82 \\
82\end{array}$ & 81 & 77.6 & $\begin{array}{r}6.5 \\
76.6\end{array}$ \\
\hline 3 & $\{73.6$ & 73.6 & 73.1 & 73 & 74 & 76. 0 & 69.8 & 66.3 & 65. 2 & 66. 2 & 67 & 66 & 60.1 & 59.5 \\
\hline & $\{74.0$ & 74.1 & 73.8 & 73 & 75 & 76.2 & 70.3 & 66.9 & 66.5 & 66.4 & 66 & & 58.9 & 59.3 \\
\hline $3 \mathrm{~A}$ & $\{75.6$ & 75.8 & 76.0 & 76 & 80 & 77.8 & 71.3 & 73.1 & 72.9 & 73.7 & 74 & 72 & 71.4 & 66.2 \\
\hline oA & 76.0 & $\begin{array}{l}75.5 \\
69.5\end{array}$ & $\begin{array}{r}76.0 \\
68\end{array}$ & 76 & 82 & 77.8 & $\begin{array}{l}71.7 \\
67\end{array}$ & 73.4 & $\begin{array}{l}74.1 \\
47.0\end{array}$ & $\begin{array}{r}72.3 \\
44.5\end{array}$ & $\begin{array}{l}74 \\
45\end{array}$ & 51 & $\begin{array}{l}70.2 \\
45.2\end{array}$ & $\begin{array}{l}64.6 \\
41.9\end{array}$ \\
\hline 4 & $\left\{\begin{array}{l}0.8 \\
71.4\end{array}\right.$ & $\begin{array}{l}09.0 \\
71.6\end{array}$ & 68.1 & $\begin{array}{l}00 \\
68\end{array}$ & 67 & 70.8 & 68.2 & 50.2 & 48.1 & $\begin{array}{l}44.9 \\
\end{array}$ & 46 & & 45.8 & 41.6 \\
\hline & $\{69.5$ & 68.8 & 65.7 & 66 & 64 & 71.3 & 66.5 & 53.4 & 50.8 & 50.9 & 51 & 52 & 45.5 & 46.9 \\
\hline $4 \mathrm{~A}$ & $\{69.8$ & 69.6 & 66.3 & 66 & 64 & 70.7 & 66.9 & 53.3 & 54.0 & 50.1 & 50 & & 46.5 & 46.7 \\
\hline 5 & $\{63.7$ & 62.6 & 61.3 & 62 & 62 & 63. 0 & 59.4 & 40.6 & 38. 9 & 37.6 & 38 & 42 & 37.5 & 33. 6 \\
\hline 5 & $\left\{\begin{array}{l}63.8 \\
\end{array}\right.$ & 63.0 & 62.4 & 62 & 64 & 62.7 & 59.5 & 40.3 & 40.6 & 37.6 & 39 & & 37.9 & 33.2 \\
\hline $5 \mathrm{~A}$ & 60.4 & 60.1 & 60.1 & 60 & 60 & 59.8 & 55.6 & 38.5 & 35. 3 & 37. 2 & 38 & 40 & 35.1 & 29.8 \\
\hline & 60.5 & 60.0 & 60.5 & 60 & 63 & 59.4 & 56.0 & 38.5 & 37.8 & 37.8 & 38 & $\cdots$ & 36.2 & 29.5 \\
\hline 6 & $\int 18.6$ & 19.2 & 18.1 & 19 & 21 & 21.4 & 14.6 & 8.2 & 9.2 & 7.8 & 8.6 & 8.3 & 9.6 & 4. 4 \\
\hline & $\mid 18.6$ & 19.5 & 18.1 & 18 & 23 & 21.2 & 14. & 8. & 9. & 7.5 & 8. & & 9.7 & 4.3 \\
\hline $6 \mathrm{~A}$ & $\left\{\begin{array}{l}16.0 \\
150\end{array}\right.$ & 16. 2 & 15.4 & 15 & 19 & 19. 7 & 11.7 & 7. 3 & 8.0 & 6.7 & 7.4 & 7.2 & 8.6 & 3.5 \\
\hline & $\begin{array}{r}10.9 \\
41.8\end{array}$ & $\begin{array}{l}10.5 \\
41.5\end{array}$ & $\begin{array}{l}10.8 \\
39.5\end{array}$ & $\begin{array}{l}16 \\
41\end{array}$ & 20 & $\begin{array}{l}18.4 \\
41.6\end{array}$ & $\begin{array}{l}11.9 \\
36.9\end{array}$ & $\begin{array}{r}7.3 \\
190\end{array}$ & $\begin{array}{r}8.3 \\
19.3\end{array}$ & $\begin{array}{r}6.5 \\
17.5\end{array}$ & $\begin{array}{r}7.3 \\
19\end{array}$ & 20 & $\begin{array}{r}8.7 \\
190\end{array}$ & $\begin{array}{r}3.4 \\
12.9\end{array}$ \\
\hline 7 & $\left\{\begin{array}{l}41.8 \\
41.8\end{array}\right.$ & $\begin{array}{l}41.5 \\
42.1\end{array}$ & $\begin{array}{l}39.5 \\
40.7\end{array}$ & $\begin{array}{l}41 \\
41\end{array}$ & $\begin{array}{l}40 \\
41\end{array}$ & $\begin{array}{l}41.0 \\
41.4\end{array}$ & $\begin{array}{l}50.0 \\
36.8\end{array}$ & $\begin{array}{l}19.0 \\
19.0\end{array}$ & $\begin{array}{l}19.0 \\
20.2\end{array}$ & $\begin{array}{l}17.2 \\
\end{array}$ & $\begin{array}{l}19 \\
19\end{array}$ & 20 & $\begin{array}{l}18.9 \\
\end{array}$ & 12.9 \\
\hline 74 & $\int 40.3$ & 40.4 & 39.3 & 40 & 41 & 41.9 & 35.6 & 19.9 & 20.4 & 19.0 & 20 & 21 & 20.4 & 14.1 \\
\hline $7 \mathrm{~A}$ & $\left\{\begin{array}{l}40.5 \\
\end{array}\right.$ & 40.5 & 40.3 & 40 & 43 & 42.0 & 35. 7 & 19.8 & 21.0 & 19.0 & 19 & & 20.2 & 14.0 \\
\hline & $\int 17.1$ & 18.8 & 17.9 & 17 & 22 & 20.9 & 13.7 & 7.5 & 9.1 & 7.9 & 7. 6 & 7. 7 & 8.3 & 3.9 \\
\hline 8 & $\left\{\begin{array}{l}17.7 \\
\text { S }\end{array}\right.$ & $\begin{array}{l}19.8 \\
\end{array}$ & 17. 8 & 18 & 23 & 20.0 & 13.6 & 7.7 & 9.1 & 7.4 & 8.2 & & 9.4 & 3.8 \\
\hline & $\int 21.0$ & 24.0 & 24.1 & 23 & 29 & 24.2 & 17.6 & 11.3 & 14. 9 & 13. 2 & 13 & 12 & 13.8 & 7.9 \\
\hline $8 \mathrm{~A}$ & 22.5 & 24.8 & 22.0 & 23 & 29 & 25.1 & 17.5 & 12.7 & 14.6 & 12.1 & 13 & & 15.0 & 7.6 \\
\hline 0 & 29.3 & 29.7 & 28.2 & 29 & 30 & 29.9 & 24.4 & 10.9 & 11.8 & 9.9 & 11 & 12 & 11.9 & 6.3 \\
\hline 9 & 29.4 & 29.8 & 28.6 & 29 & 31 & 30.0 & 24.5 & 11.8 & 12. 2 & 9.7 & 11 & & 11.9 & 6.2 \\
\hline & 26.2 & 26.4 & 25.2 & 26 & 27 & 27.0 & 21.4 & 9.6 & 10.4 & 8.4 & 9.8 & 9.7 & 11.0 & 5.4 \\
\hline $9 \mathrm{~A}$ & 26.1 & 26.6 & 25.2 & 26 & 28 & 27.2 & 21.5 & 9.6 & 10.6 & 8.5 & 9.7 & & 10.7 & 5.3 \\
\hline 10 & f 8.5 & 9.4 & 7.6 & 8. 6 & 9.0 & 9.4 & 5.1 & 1.8 & 2.4 & 1.4 & 1.9 & 1.9 & 2.8 & 0.0 \\
\hline 10 & 8.5 & 9.4 & 7.7 & 8. 6 & 10.0 & 9.3 & 5.1 & 1.8 & 2. 5 & 1.4 & 1.9 & & 2.8 & 0.0 \\
\hline $10 \mathrm{~A}$ & $\left\{\begin{array}{l}7.4 \\
\text { f }\end{array}\right.$ & 8.0 & 6.8 & 7.4 & 8.0 & 8.4 & 4.0 & 1.6 & 2. 2 & 1.4 & 1.9 & 1.6 & 2.6 & 0.0 \\
\hline & 7.4 & 8.2 & 6.8 & 7.4 & 8.0 & 8.4 & 4. 0 & 1.6 & 2. 2 & 1.3 & 1.8 & .... & 2.6 & 0.0 \\
\hline $\mathrm{G}: 1$ & $\{79.1$ & 76.7 & 76.6 & 75 & 76 & 75.6 & 70.7 & 70.4 & 67.2 & 71.1 & 67 & 68 & 48.0 & 46. 9 \\
\hline G1 & & 77.7 & 78 & 76 & 76 & & & & 70.7 & 70.1 & 67 & & 46.7 & 48.3 \\
\hline & $\{82.7$ & 82.4 & 83.2 & 82 & 80 & 84 & 77.6 & 76.3 & 75.0 & 78.2 & 76 & 75 & 75.3 & 68.0 \\
\hline G2 & $\left\{\begin{array}{l}0.1 \\
83.7\end{array}\right.$ & 83.7 & 83.3 & 83 & 84 & 85.0 & 78.3 & 78.0 & 77.2 & 78.2 & 76 & 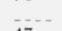 & 77.1 & 68.1 \\
\hline & $\{63.5$ & 60.8 & 59.3 & 60 & 60 & 61.1 & 54.4 & 49.6 & 43. 3 & 43. 2 & 44 & 47 & 45.0 & 37.6 \\
\hline G3 & $\{62.6$ & 58.7 & 58.7 & 60 & 64 & 61.6 & 54.6 & 48.7 & 44. 4 & 43.1 & 45 & & 44.4 & 37.0 \\
\hline $\mathrm{GH}_{4}$ & 67.6 & 64.0 & 67.4 & 67 & 70 & 69.8 & 61.6 & 57.8 & 53. 6 & 57.8 & 54 & 57 & 59.0 & 49. 0 \\
\hline $\mathrm{G}_{4} 4$ & 67.6 & 66.6 & 68.3 & 66 & 74 & 68. 6 & 62.4 & 57.7 & 56. 3 & 57. 2 & 54 & & 58.6 & 47.4 \\
\hline & 79.8 & 78.2 & 79.2 & 79 & 80 & 79.1 & 73.0 & 64.1 & 59.7 & 64. 2 & 64 & 67 & 54.6 & 52.5 \\
\hline G5 & $\left\{\begin{array}{r}8.9 \\
0.9\end{array}\right.$ & 78.3 & 80.9 & 79 & 80 & 78.9 & 73.7 & 65.4 & 63.4 & 64.5 & 64 & .... & 55.5 & 52.3 \\
\hline G6 6 & $\left\{\begin{array}{r}59.3 \\
59.4\end{array}\right.$ & $\begin{array}{l}57.2 \\
57.6\end{array}$ & $\begin{array}{l}55.8 \\
57.4\end{array}$ & $\begin{array}{l}58 \\
58\end{array}$ & $\begin{array}{l}56 \\
59\end{array}$ & $\begin{array}{l}58.7 \\
58.4\end{array}$ & $\begin{array}{l}53.2 \\
53.7\end{array}$ & $\begin{array}{l}32.0 \\
32.0\end{array}$ & $\begin{array}{l}32.5 \\
33.5\end{array}$ & $\begin{array}{l}29.3 \\
29.6\end{array}$ & $\begin{array}{l}32 \\
31\end{array}$ & 35 & $\begin{array}{l}30.7 \\
30.8\end{array}$ & $\begin{array}{l}25.0 \\
24.7\end{array}$ \\
\hline
\end{tabular}

TABLE 2. Variance of laboratories for $G_{L}$ and $G_{S}$ determinations

\begin{tabular}{|c|c|c|}
\hline \multirow{2}{*}{ Laboratory } & \multicolumn{2}{|c|}{$s_{j}^{2}$} \\
\hline & $G_{L}$ & $G_{S}$ \\
\hline $\begin{array}{l}1 \\
2 \\
3 \\
4 \\
5 \\
6 \\
7\end{array}$ & $\begin{array}{r}0.196 \\
.330 \\
.360 \\
.154 \\
.847 \\
.152 \\
.108\end{array}$ & $\begin{array}{r}0.152 \\
.727 \\
.179 \\
.144 \\
-.396 \\
.188\end{array}$ \\
\hline
\end{tabular}

\section{b. Reproducibility}

The variance for the average of six laboratories, each laboratory result being made up of two duplicate readings, is

$$
\left[\sigma_{L}^{2}+\left(\sigma^{2} / 2\right)\right] / 6,
$$

where $\sigma_{L}^{2}$ is the variability between laboratories and $\sigma^{2}$ is the variance within laboratories. The variability between laboratories for $G_{L}$ is 2.07 and for $G_{S}$ is 2.21 . This analysis may be represented thus:

\begin{tabular}{|c|c|c|}
\hline & $\sigma^{2}\left(G_{L}\right)$ & $\sigma^{2}\left(G_{S}\right)$ \\
\cline { 2 - 3 } & & \\
Variance of a laboratory average of & & \\
two rea dings & 2.18 & 2.21 \\
Variance of 6 laboratories average $\ldots$ & 0.36 & 0.37 \\
\hline
\end{tabular}

This analysis shows that the reproducibility of $G_{L}$ and $G_{S}$ is approximately equal and the variance in both is reasonably small for the average of 6 laboratories, but is somewhat large for 1 laboratory average of 2 duplicate readings. 


\section{c. Specimen Classification}

The data shown in figure 9 are the arithmetic mean values of readings obtained with the small aperture, $G_{S}$, plotted against arithmetic mean values of readings obtained with the large aperture, $G_{L}$. Because the errors in readings for $G_{L}$ and $G_{S}$ are correlated, simple functions of $G_{L}$ and $G_{S}$ are desired in which the errors are uncorrelated. These statistically uncorrelated functions would be useful for the final discrimination of gloss characteristics, that are, however, functionally related. Two simple functions, which seem to work well, are the sums, $S$, and differences, $D$ :

$$
\begin{aligned}
& S=G_{L}+G_{S} \\
& D=G_{L}-G_{S} .
\end{aligned}
$$

If only the determinations $G_{L}$ and $G_{S}$ are used for discrimination, the statistical correlations between them may obscure the discrimination between different gloss characteristics. Use of $S$ and $D$ accentuates the ability to discriminate gloss characteristics.

The fact that $S$ and $D$ are statistically uncorrelated can be demonstrated by the following simple argument. The correlation between $S$ and $D$ is given [14] by

$$
\rho(S, D)=E[(S-\bar{S})(D-\bar{D})] / \sigma(S) \sigma(D),
$$

where $E$ is read as "the expected value of"; $\overline{\mathrm{S}}$ and $\overline{\mathrm{D}}$ are the mean values of $S$ and $D$, respectively. When $G_{L}+G_{S}$ is substituted for $S$ and $G_{L}-G_{S}$ is substituted for $D$ in eq (12), the following expression for the correlation between $S$ and $D$ results:

$$
\rho(S, D)=\frac{\sigma^{2}\left(G_{L}\right)-\sigma^{2}\left(G_{S}\right)}{\sigma(S) \sigma(D)}
$$

Experimental results, discussed above, indicate that the variances, $\sigma^{2}\left(G_{L}\right)$ and $\sigma^{2}\left(G_{S}\right)$ are equal. Thus

$$
\rho(S, D)=0 .
$$

Figure 10 shows a plot of the $D$ versus $S$ values for the data of figure 9 .

\section{Two-Parameter Method and Subjective Evaluation}

The two-parameter (receptor aperture) method was found to correlate with goniophotometric curve evaluation in that three groups are established by both methods, each containing essentially the same specimens in essentially the same order (see figs. 8 and 10). Correlation between subjective and instrumental evaluation is required to esablish firmly the utility of the two-parameter method.

\subsection{Image Distinctness and Constant Image Brightness}

A test was arranged to determine whether image distinctness could be evaluated as the two-parameter method evaluates it, when variation in brightness is minimized. Twelve sets of three specimens, each set of approximately equal brightness $\left(G_{L}\right)$, were selected from the 26 specimens and presented to the observers.

The source was a bank of fluorescent lamps. The standards were placed on a table so that images of the lamps were reflected at a specular angle of approximately $60^{\circ}$. The observers were asked to arrange the specimens in order of image distinctness, indicating ties where necessary. The selected sets of three specimens are listed in table 3, together with the corresponding $G_{L}$ values. Image distinctness in each set of triplets increased from left to right and are given numbers 1,2 , and 3 , respectively. In set 11 , specimens 3 and $3 \mathrm{~A}$ are from the same family of image distinctness and are both ranked 2.5.

\begin{tabular}{|c|c|c|c|c|c|c|}
\hline \multirow{2}{*}{$\begin{array}{c}\text { Set } \\
\\
1 \\
2 \\
3 \\
4 \\
5\end{array}$} & \multicolumn{3}{|c|}{ Specimens a } & \multicolumn{3}{|c|}{ Corresponding $G_{L}$} \\
\hline & $\begin{array}{l}1 \\
1 \mathrm{~A} \\
\text { G5 } \\
\text { G5 } \\
\text { G5 }\end{array}$ & $\begin{array}{r}\mathrm{G} 2 \\
2 \\
2 \\
\mathrm{G} 1 \\
\mathrm{G} 2\end{array}$ & $\begin{array}{l}2 \mathrm{~A} \\
2 \mathrm{~A} \\
2 \mathrm{~A} \\
3 \\
3 \mathrm{~A}\end{array}$ & $\begin{array}{l}90 \\
88 \\
79 \\
79 \\
79\end{array}$ & $\begin{array}{l}83 \\
84 \\
84 \\
77 \\
83\end{array}$ & $\begin{array}{l}86 \\
86 \\
86 \\
74 \\
77\end{array}$ \\
\hline $\begin{array}{r}6 \\
7 \\
8 \\
9 \\
10\end{array}$ & $\begin{array}{r}\text { G5 } \\
4 \\
4 \\
4 \\
9 \mathrm{~A}\end{array}$ & $\begin{array}{r}\mathrm{G} 1 \\
\mathrm{G} 1 \\
\mathrm{G} 1 \\
\mathrm{G} 4 \\
6\end{array}$ & $\begin{array}{l}3 \mathrm{~A} \\
3 \mathrm{~A} \\
3 \\
3 \\
8 \mathrm{~A}\end{array}$ & $\begin{array}{l}79 \\
69 \\
69 \\
69 \\
26\end{array}$ & $\begin{array}{l}77 \\
77 \\
77 \\
68 \\
20\end{array}$ & $\begin{array}{l}77 \\
77 \\
74 \\
74 \\
24\end{array}$ \\
\hline $\begin{array}{l}11 \\
12\end{array}$ & $\begin{array}{r}\mathrm{G} 1 \\
5\end{array}$ & $\begin{array}{r}\text { b } 3 \\
\text { c } 4 \mathrm{~A}\end{array}$ & $\begin{array}{l}\text { b } 3 \mathrm{~A} \\
\text { c } \mathrm{G} 3\end{array}$ & $\begin{array}{l}77 \\
63\end{array}$ & $\begin{array}{l}74 \\
67\end{array}$ & $\begin{array}{l}77 \\
61\end{array}$ \\
\hline
\end{tabular}
Similarly, specimens $4 \mathrm{~A}$ and G3 of set 12 are ranked 2.5 .

TABLE 3. Sets of three specimens for evaluation of I with constant $G_{L}$

a Image distinctness increases from left to right in each set of triplets, and are given numbers $1,2,3$, respectively.

Same image family.

c Same image family.

The results of this test are listed in table $4 . \quad$ As a measure of agreement between ranking given by the $m$ judges and ranking assigned by $G_{S}$ of the two-parameter method, an average of $m$ rank correlations was determined. The Spearman rank correlation coefficient was used, and the average is indicated by $\bar{R}_{S}$. If $\left(X_{1}, X_{2}, X_{3}\right)$ is the assigned ranking of three objects and $\left(Y_{i 1}, Y_{i 2}, Y_{i 3}\right)$, for $i=1$ to $m$, are the rankings given by the $m$ judges, then,

$$
\begin{aligned}
\bar{R}_{s} & =\frac{1}{m} \sum_{1}^{m}\left\{\sum_{1}^{3}\left(X_{j} Y_{i j}-4\right) / 2\right\} \\
& =\frac{1}{2 m} \sum_{1}^{3}\left\{X_{j}\left(\sum_{1}^{m} Y_{i j}\right)-4 m\right\} .
\end{aligned}
$$

The results of the computation of $\overline{R_{S}}$ for these specimens show quite good agreement between the assigned and the given rankings. 
TABLE 4. Rankings of triplets by 10 judges

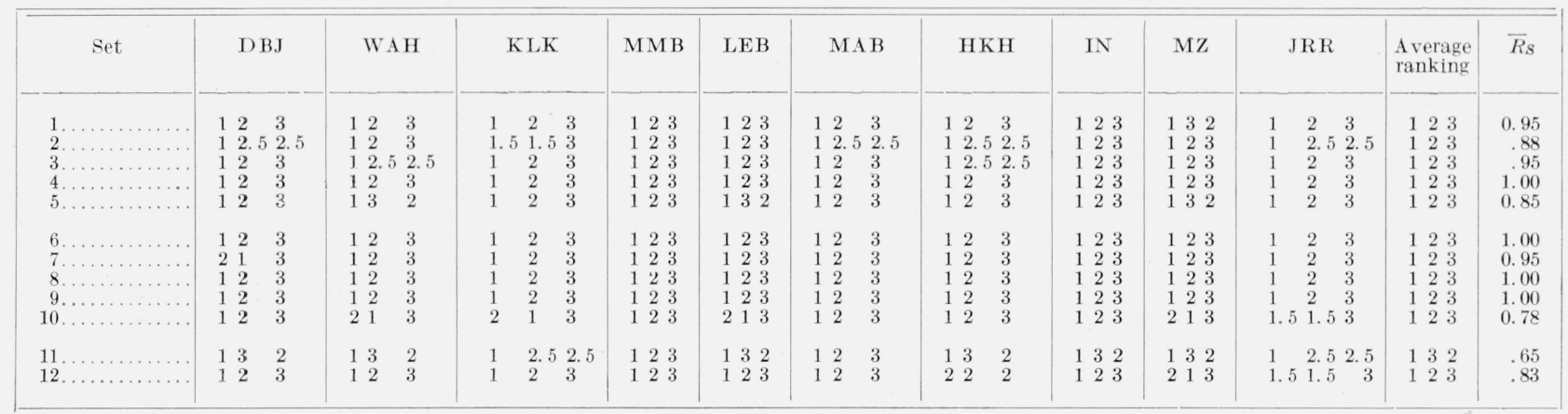

To measure the agreement among judges without reference to the "correctness" of what they agree upon, Kendall's coefficient of concordance [15], $W$, was used.

$$
W=\frac{12 \sum_{1}^{3}{ }_{j}\left(\sum_{1}^{10}{ }_{i} Y_{i j}-20\right)^{2}}{2400-10 \sum_{1}^{10}\left(t_{i}^{3}-t_{i}\right)},
$$

where

$$
t_{i}=\left\{\begin{array}{l}
0 \text { for no ties } \\
2 \text { for two specimens tied } \\
3 \text { for three specimens tied }
\end{array}\right.
$$

The results of the computation of $W$ are listed in table 5. These results show a high concord ance among the judges for the 12 sets selected.

We may therefore conclude that, where the image brightness range is not great, image distinctness is evaluated by the two-parameter method in accord with subjective evaluation. Thus the two-parameter method may be considered to be a successful technique for evaluating image distinctness when image brightness is ratatively constant.

TABLE 5. Measure of agreement among judges, Kendall's

\begin{tabular}{|c|c|}
\hline Set & $W$ \\
\hline $\begin{array}{l}1 \\
2 \\
3 \\
4 \\
5\end{array}$ & $\begin{array}{r}0.91 \\
.89 \\
.96 \\
1.00 \\
0.79\end{array}$ \\
\hline $\begin{array}{l}6 \\
7 \\
8 \\
9 \\
10\end{array}$ & $\begin{array}{l}1.00 \\
0.91 \\
1.00 \\
1.00 \\
0.77\end{array}$ \\
\hline $\begin{array}{l}11 \\
12\end{array}$ & $\begin{array}{l}.83 \\
.80\end{array}$ \\
\hline Average & 0.90 \\
\hline
\end{tabular}
coefficient of concordance, $W$

\section{Summary}

A complete description of the gloss characteristics of any specimen requires multiparameter data, obtained on either a multi slane or a monoplane gonio- photometer. For reasons of economy simpler techniques are sought that can adequately describe the gloss characteristics of any specimen. The simplest method, using one parameter, does not always provide a sufficient description.

Two-parameter gloss methods provide more adequate description of the gloss of specimens than do one-parameter methods. A two-parameter technique employing specular reflection measurement for two incidence angles reveal specimen incidence-angle dependency. A gloss index may state the difference of specular reflectance for a difference of specular angle, $d G / d \theta$.

A two-parameter technique employing specular reflection measurement with a large and a small receptor aperture will reveal the existence of more than one gloss type. A specification may state the ranges of $G_{L}$ and $G_{S}$, or $S$ and $D$, thereby indicating the desired surface-appearance type.

The author thanks M. Zelen and Joan R. Rosenblatt for advice and assistance in the analysis of the round-robin data and the subjective evaluations, and W. A. Hall for assistance in this investigation.

\section{References}

[1] H. J. MeNicholas, J. Research NBS 13, 211 (1934) RP704.

[2] F. Thaler, Ann. Physik [4] 11, 996 (1903).

[3] L. A. Wetlaufer and W. E. Scott, Ind. Eng. Chem., Anal. Ed. 12, 647 (1940).

[4] P. Moon and J. Laurence, J. Opt. Soc. Am. 31, 130 (1941).

[5] H. K. Hammond and I. Nimeroff, J. Research NBS 44, 585 (1950) RP2105.

[6] W. E. K. Middleton and A. G. Mungall, J. Opt. Soc. Am. 42, 572 (1952).

[7] W. W. Barkas, Proc. Phys. Soc. (London) 51, 274 (1939). [8] ASTM Standards Suppl. 6, 434 (1954).

[9] C. L. Dows and G. R. Baumgartner, Trans. Illum. Eng. Soc. 30, 746 (1935).

[10] I. Nimeroff, J. Research NBS 48, 441 (1952) RP2335.

[11] ASTM Book of Standards 6, 695 (1952).

[12] W. E. K. Middleton and A. G. Mungall, Can. J. Technol. 31, 160 (1953).

[13] ASTM Standards Suppl. 4, 84 (1953).

[14] A. McF. Mood, Introduction to the theory of statistics (McGraw-Hill Book Co., Inc., New York, N. Y., 1950).

[15] M. G. Kendall, Rank correlation methods (Charles Griffin \& Co., Ltd., 1948).

Washington, April 19, 1956. 